\title{
PECULIARITIES OF BONE MINERAL DENSITY IN WOMEN OF DIFFERENT REPRODUCTIVE AGE WITH SYSTEMIC LUPUS ERYTHEMATOSUS
}

D0l:10.36740/WLek202102124

\author{
Sergii V. Shevchuk', Liudmyla P. Denyshchych', Liubov I. Marynych', Inna P. Kuvikova², Iryna V. Kurilenko², \\ Olena V. Shevchuk' \\ 'NATIONAL PIROGOV MEMORIAL MEDICAL UNIVERSITY, VINNYTSIA, UKRAINE \\ ${ }^{2}$ SCIENTIFIC AND RESEARCH INSTITUTE OF INVALID REHABILATATION (EDUCATIONAL SCIENTIFIC TREATMENT COMPLEX) OF NATIONAL PIROGOV \\ MEMORIAL MEDICAL UNIVERSITY, VINNYTSIA, UKRAINE
}

\begin{abstract}
The aim: To study the peculiarities of bone mineral density in the Ukrainian population of women of different reproductive age with systemic lupus erythematosus and to evaluate its connection with traditional and specific (typical for systemic lupus erythematosus) risk factors.

Materials and methods: A total of 91 women with systemic lupus erythematosus and 29 healthy individuals were examined. Along with the clinical study of the activity and severity of the disease, the serum levels of interleukin- 6 were determined by the enzyme immunoassay. The peculiarities of bone mineral density were studied using dual-energy $X$-ray absorptiometry. The presence of fractures was evaluated by the $X$-ray method.

Results: Patients with systemic lupus erythematosus frequently suffer from reduced bone mineral density. Reduced bone mineral density and the appearance of fragility fractures are associated with patients' age, disease duration, damage index, inflammatory activity, and cumulative dose of glucocorticoids.

Conclusions: Progressive reduced bone mineral density in patients with systemic lupus erythematosus occurs not only during the aging process of a woman, but is also associated with a number of systemic lupus erythematosus - related osteoporosis risk factors.
\end{abstract}

KEY WORDS: osteoporosis, fragility fractures, glucocorticoids, interleukin-6

Wiad Lek. 2021;74(2):303-309

\section{INTRODUCTION}

Nowadays, the worldwide interest of scientists to osteoporosis is primarily motivated by the high prevalence of both the disease itself and its consequences - limb and spine fractures, which cause temporary and permanent disability, poor quality of life and increased mortality [1].

Recent studies have shown a high incidence of osteoporosis and fragility fractures in patients with systemic lupus erythematosus (SLE) compared with the general population $[2,3]$.

The development of osteoporosis in patients with SLE is thought to be mainly associated with the use of glucocorticoids (GCs) and hyperproduction of cytokines, which negatively affect bone metabolism $[4,5]$. The significance of the above mentioned factors is proved by the fact that the reduced bone mineral density (BMD) in the lumbar spine and hip in SLE patients who received large doses of prednisone and suffered from active inflammation is significantly higher than in those with low-grade or moderate-grade inflammation and/or low-dose use of GCs $[5,6]$. Disorders of bone metabolism, development of osteoporosis and its complications in SLE patients are caused not only by disease-specific risk factors, but also by traditional ones, such as sex, motor activity, lifetime, diet, which alone or in combination affect the patients' health. [2]. There are few comprehensive studies of the role of traditional and SLE-specific risk factors for the development of BMD disorders in the world literature, and practically none in Ukraine.

\section{THE AIM}

Taking into consideration all mentioned above, the aim of this study is to investigate the bone mineral density in Ukrainian women of different reproductive age with systemic lupus erythematosus and to evaluate its connection with traditional and specific (typical for SLE) risk factors.

\section{MATERIALS AND METHODS}

91 women with SLE (the main group) participated in the study. The average age of patients was $45.11 \pm 1.03$ years. The control group consisted of 29 healthy individuals of the same age and sex (average age $-46.79 \pm 2.30$ years). The diagnosis of SLE was established on the basis of 2019 European League Against Rheumatism/American College of Rheumatology classification criteria for systemic lupus 
Table I. BMD in SLE women of different reproductive age and control group

\begin{tabular}{|c|c|c|c|c|}
\hline & Indicator & Characteristic & Control group & SLE patients \\
\hline \multicolumn{5}{|c|}{ Reproductive period } \\
\hline \multirow{2}{*}{1} & \multirow{2}{*}{ Z-score $\leq-2.0$ SD } & Lumbar spine, $n=13 / 53$ & $0(0 \%)$ & $5(9.4 \%)^{*}$ \\
\hline & & Hip, $n=13 / 32$ & $0(0 \%)$ & $3(9.4 \%)^{*}$ \\
\hline \multirow{2}{*}{2} & \multirow{2}{*}{ Z-score > - 2.0 SD } & Lumbar spine, $n=13 / 53$ & $13(100 \%)$ & $46(90.6 \%)^{*}$ \\
\hline & & Hip, $n=13 / 32$ & $13(100 \%)$ & $29(90.6 \%)^{*}$ \\
\hline \multirow{2}{*}{3} & \multirow{2}{*}{ Z-score, average, SD } & Lumbar spine, $n=13 / 53$ & $-0.10 \pm 0.15$ & $-0.65 \pm 0.14^{*}$ \\
\hline & & Hip, $n=13 / 32$ & $-0.07 \pm 0.13$ & $-0.59 \pm 0.16^{*}$ \\
\hline \multirow{2}{*}{4} & \multirow{2}{*}{$\mathrm{BMD}, \mathrm{g} / \mathrm{cm} 2$} & Lumbar spine, $n=13 / 53$ & $0.94 \pm 0.04$ & $0.92 \pm 0.02$ \\
\hline & & Hip, $n=13 / 32$ & $1.00 \pm 0.05$ & $0.92 \pm 0.03$ \\
\hline \multirow{3}{*}{5} & \multicolumn{4}{|c|}{ Postmenopause } \\
\hline & \multirow{2}{*}{ Osteoporosis, T-score at or below -2.5 SD } & Lumbar spine, $n=16 / 38$ & $1(6,3 \%)$ & $7(18,4 \%)$ \\
\hline & & Hip, $n=16 / 22$ & $1(6,3 \%)$ & $3(13,6 \%)$ \\
\hline \multirow{2}{*}{6} & \multirow{2}{*}{$\begin{array}{l}\text { Osteopenia, T-score between }-1.0 \text { and } \\
-2.5 \text { SD }\end{array}$} & Lumbar spine, $\mathrm{n}=16 / 38$ & $4(25.0 \%)$ & $19(50.0 \%)^{*}$ \\
\hline & & Hip, $n=16 / 22$ & $4(25.0 \%)$ & $10(45.4 \%)$ \\
\hline \multirow{2}{*}{7} & \multirow{2}{*}{ Normal, T-score at -1.0 SD and above } & Lumbar spine, $n=16 / 38$ & $8(50.0 \%)$ & $12(31.5 \%)$ \\
\hline & & Hip, $n=16 / 22$ & $10(62.5 \%)$ & $9(40.9 \%)$ \\
\hline \multirow{2}{*}{8} & \multirow{2}{*}{ T-score, average, SD } & Lumbar spine, $\mathrm{n}=16 / 38$ & $-1.02 \pm 0.17$ & $-1.29 \pm 0.18$ \\
\hline & & Hip, $n=16 / 22$ & $-0.82 \pm 0.14$ & $-1.0 \pm 0.2$ \\
\hline \multirow{2}{*}{9} & \multirow{2}{*}{$\mathrm{BMD}, \mathrm{g} / \mathrm{cm} 2$} & Lumbar spine, $\mathrm{n}=16 / 38$ & $0.99 \pm 0.03$ & $0.88 \pm 0.02 *$ \\
\hline & & Hip, $n=16 / 22$ & $1.01 \pm 0.03$ & $0.93 \pm 0.03$ \\
\hline 10 & Total number of people with de & sed $B M D, n=29 / 91$ & $5(17.2 \%)$ & $32(35.2 \%)^{*}$ \\
\hline \multirow{2}{*}{11} & \multirow{2}{*}{ Average BMD, g/cm2 } & Lumbar spine, $\mathrm{n}=29 / 91$ & $0.97 \pm 0.02$ & $0.90 \pm 0.01^{*}$ \\
\hline & & Hip, $n=29 / 54$ & $1.02 \pm 0.03$ & $0.93 \pm 0.02^{*}$ \\
\hline \multirow{2}{*}{12} & \multirow{2}{*}{ Total number of people with fractures } & Lumbar spine, $n=29 / 91$ & $1(3.4 \%)$ & $9(9.9 \%)$ \\
\hline & & Hip, n =29/91 & $2(6.9 \%)$ & $4(4.4 \%)$ \\
\hline
\end{tabular}

Note: * - significant $(p<0.05)$ differences regarding control group.

Table II. BMD of lumbar spine and hip in SLE patients depending on their age

\begin{tabular}{|c|c|c|c|c|c|}
\hline \multirow{2}{*}{\multicolumn{3}{|c|}{$\begin{array}{l}\text { Groups of patients } \\
\text { Indicator }\end{array}$}} & \multicolumn{3}{|c|}{ Age groups, years } \\
\hline & & & \multirow{2}{*}{$\frac{\mathbf{2 2 - 3 5}}{29.1 \pm 0.92}$} & \multirow{2}{*}{$\frac{36-55}{46.5 \pm 0.68^{*}}$} & \multirow{2}{*}{$\frac{>\mathbf{5 5}}{59.2 \pm 0.71^{*}}$} \\
\hline 1 & & & & & \\
\hline 2 & Number o & e group, $n$ & 16 & 63 & 12 \\
\hline 3 & Total number & lecreased BMD & $0(0 \%)$ & $23(36.5 \%)^{*}$ & $9(75.0 \%)^{*}$ \\
\hline 4 & Total numb & th fractures & $0(0 \%)$ & $8(12.7 \%)^{*}$ & $5(41.7 \%)^{*}$ \\
\hline \multirow{3}{*}{5} & \multirow{3}{*}{ Lumbar spine } & T-score, SD & $-0.58 \pm 0.19$ & $-1.20 \pm 0.14^{*}$ & $-1.31 \pm 0.42$ \\
\hline & & $\mathrm{BMD}, \mathrm{g} / \mathrm{cm} 2$ & $0.98 \pm 0.02$ & $0.89 \pm 0.02^{*}$ & $0.88 \pm 0.05$ \\
\hline & & Z-score, SD & $-0.62 \pm 0.15$ & $-0.68 \pm 0.14$ & $-0.53 \pm 0.50$ \\
\hline 6 & \multicolumn{2}{|c|}{ Number of surveyed in the group, $n$} & 9 & 37 & 8 \\
\hline \multirow{3}{*}{7} & \multirow{3}{*}{ Hip } & T-score, SD & $-0.11 \pm 0.25$ & $-1.08 \pm 0.16^{*}$ & $-1.13 \pm 0.31^{*}$ \\
\hline & & $\mathrm{BMD}, \mathrm{g} / \mathrm{cm} 2$ & $1.01 \pm 0.04$ & $0.92 \pm 0.02^{*}$ & $0.90 \pm 0.06$ \\
\hline & & Z-score, SD & $-0.08 \pm 0.22$ & $-0.79 \pm 0.16^{*}$ & $-0.70 \pm 0.35$ \\
\hline
\end{tabular}

Note: ${ }^{*}$ - significant $(p<0.05)$ differences regarding patients of the smallest age group.

erythematosus [7]. The activity of SLE was evaluated by Systemic Lupus Erythematosus Disease Activity Index (SLEDAI) [8]. Internal organs damage was determined using Systemic Lupus International Collaborating Clinics/ American College of Rheumatology damage index (SLICC/ ACR DI) [9]. All patients received glucocorticoids and 
Table III. BMD in SLE patients depending on the duration of the disease

\begin{tabular}{|c|c|c|c|c|c|}
\hline & \multirow{2}{*}{\multicolumn{2}{|c|}{ Indicator }} & \multicolumn{3}{|c|}{ Duration of the disease, years } \\
\hline & & & $<6$ & 6-10 & $>10$ \\
\hline 1 & \multicolumn{2}{|c|}{ Duration of the disease, years } & $2.7 \pm 0.39$ & $7.9 \pm 0.30^{*}$ & $19.0 \pm 1.07^{*}$ \\
\hline 2 & \multicolumn{2}{|c|}{ Number of surveyed in the group, $\mathrm{n}$} & 23 & 16 & 52 \\
\hline 3 & \multicolumn{2}{|c|}{ Total number of people with decreased BMD } & $2(8.7 \%)$ & $4(25.0 \%)$ & $26(50.0 \%)^{*}$ \\
\hline 4 & \multicolumn{2}{|c|}{ Total number of people with fractures } & $2(8.7 \%)$ & $2(12.5 \%)$ & $9(17.3 \%)$ \\
\hline \multirow{3}{*}{5} & \multirow{3}{*}{ Lumbar spine } & T-score, SD & $-0.57 \pm 0.19$ & $-1.26 \pm 0.24^{*}$ & $-1.29 \pm 0.17^{*}$ \\
\hline & & $\mathrm{BMD}, \mathrm{g} / \mathrm{cm} 2$ & $0.97 \pm 0.02$ & $0.89 \pm 0.03^{*}$ & $0.88 \pm 0.02^{*}$ \\
\hline & & Z-score, SD & $-0.35 \pm 0.20$ & $-0.73 \pm 0.19$ & $-0.64 \pm 0.17$ \\
\hline \multirow[t]{2}{*}{6} & \multicolumn{2}{|c|}{ Number of surveyed in the group, $n$} & 8 & 9 & 37 \\
\hline & \multirow{3}{*}{ Hip } & T-score, SD & $-0.19 \pm 0.38$ & $-0.73 \pm 0.31$ & $-1.11 \pm 0.15^{*}$ \\
\hline \multirow[t]{2}{*}{7} & & $\mathrm{BMD}, \mathrm{g} / \mathrm{cm} 2$ & $1.03 \pm 0.07$ & $0.92 \pm 0.05$ & $0.91 \pm 0.02$ \\
\hline & & Z-score, SD & $-0 . .6 \pm 0.32$ & $-0.51 \pm 0.35$ & $-0.80 \pm 0.16$ \\
\hline
\end{tabular}

Note: ${ }^{*}$ - significant differences $(p<0.05)$ regarding patients with disease duration up to 6 years.

Table IV. BMD of the lumbar spine and hip in SLE patients depending on the cumulative dose of glucocorticoids

\begin{tabular}{|c|c|c|c|c|c|}
\hline & \multirow{2}{*}{$\begin{array}{l}\text { Groups of patients } \\
\text { Indicator }\end{array}$} & \multicolumn{4}{|c|}{ Cumulative dose of glucocorticoids, $\mathbf{g}$} \\
\hline & & & $<19.0$ & 19.0-70.7 & $>70.7$ \\
\hline 1 & \multicolumn{2}{|c|}{ Average cumulative dose of glucocorticoids, $\mathrm{g}$} & $9.23 \pm 1.19$ & $43.0 \pm 2.43^{*}$ & $93.1 \pm 5.97^{*}$ \\
\hline 2 & \multicolumn{2}{|c|}{ Number of surveyed in the group, $\mathrm{n}$} & 24 & 44 & 23 \\
\hline 3 & \multicolumn{2}{|c|}{ Number of people with reduced BMD } & $1(4.1 \%)$ & $20(45,4 \%)^{*}$ & $11(47.8 \%)^{*}$ \\
\hline 4 & \multicolumn{2}{|c|}{ Number of people with fractures } & $1(4.2 \%)$ & $8(18,2 \%)^{*}$ & $4(17.4 \%)$ \\
\hline \multirow{3}{*}{5} & \multirow{3}{*}{ Lumbar spine } & T-score, SD & $-0.48 \pm 0.25$ & $-1.23 \pm 0.11$ & $-1.63 \pm 0.22^{*}$ \\
\hline & & $\mathrm{BMD}, \mathrm{g} / \mathrm{cm} 2$ & $0.98 \pm 0.03$ & $0.89 \pm 0.01^{*}$ & $0.84 \pm 0.02^{*}$ \\
\hline & & Z-score, SD & $-0.11 \pm 0.28$ & $-0.72 \pm 0.11$ & $-0.98 \pm 0.21^{*}$ \\
\hline 6 & \multicolumn{2}{|c|}{ Number of surveyed in the group, $n$} & 8 & 31 & 15 \\
\hline \multirow{3}{*}{7} & \multirow{3}{*}{ Hip } & T-score, SD & $-0.43 \pm 0.33$ & $-0.82 \pm 0.15$ & $-1.37 \pm 0.25^{*}$ \\
\hline & & $\mathrm{BMD}, \mathrm{g} / \mathrm{cm} 2$ & $0.99 \pm 0.04$ & $0.94 \pm 0.03$ & $0.87 \pm 0.03^{*}$ \\
\hline & & Z-score, SD & $-0.46 \pm 0.31$ & $-0.70 \pm 0.17$ & $-0.88 \pm 0.27$ \\
\hline
\end{tabular}

Note: * significant differences $(p<0.05)$ regarding patients with cumulative dose of glucocorticoids up to $19 \mathrm{~g}$.

did not use other immunosuppressive agents. Partvicular attention was paid to the study of musculoskeletal system and the presence of traditional and SLE-related risk factors for osteoporosis: age, menstrual status, duration of the disease, activity of the inflammatory process, cumulative dose of glucocorticoids, fragility fractures.

The laboratory examination included determination of serum level of interleukin-6 (IL-6) by enzyme immunoassay.

The presence of vertebral fractures was assessed by Genant semi-quantitative method, which requires a $20 \%$ decrease in vertebral height on lateral thoracolumbar radiographs. Patients who had a history of femoral neck fractures had X-ray of both hip.

Changes in BMD of the lumbar spine at the level of L1-L4 and the proximal femur were determined by dual-energy $\mathrm{X}$-ray densitometry (DXA) on Hologic Discovery Wi (S / N 87227). The results of BMD determination were expressed in absolute values as well as T- and Z-score. Osteoporosis was diagnosed if the T-score in postmenopausal women of the lumbar vertebrae (L1-L4) and/or proximal femur was $-2.5 \mathrm{SD}$ (standard deviation) or less. Osteopenia met T-score from -1.0 to $-2.5 \mathrm{SD}$. In women of reproductive age, the Z-score was used to determine BMD. Values of the $\mathrm{Z}$-score $\leq-2.0 \mathrm{SD}$ were considered as "below the expected range for age". The group of patients with reduced BMD included women of reproductive age with $\mathrm{Z}$-score $\leq-2.0$ $\mathrm{SD}$ and post-menopausal women with T-score $<-1.0 \mathrm{SD}$.

The study was carried out in compliance with the provisions of the Council of Europe Convention on Human Rights and Biomedicine, Declaration of Helsinki and recommendations of the Committee on Bioethics of the Presidium of National Academy of Medical Sciences of Ukraine.

Statistical analysis of the results was carried out using standard methods with Excel 10.0 application package and using the program "SPSS-10.0.5 for Windows" (license number 305147890). Average value (M) and standard errors $(\mathrm{m})$ were evaluated. The normality of the distribution 
Table V. BMD of lumbar spine and hip in SLE patients depending on DI and SLEDAI

\begin{tabular}{|c|c|c|c|c|c|c|}
\hline & \multirow{2}{*}{\multicolumn{2}{|c|}{ Groups of patients }} & \multicolumn{2}{|c|}{ DI, points } & \multicolumn{2}{|c|}{ SLEDAI, points } \\
\hline & & & $<4$ & $\geq 4$ & $<20$ & $\geq \mathbf{2 0}$ \\
\hline 1 & \multicolumn{2}{|c|}{ Number of surveyed, $\mathrm{n}$} & 52 & 39 & 67 & 24 \\
\hline 2 & \multicolumn{2}{|c|}{ Number of people with reduced BMD } & $10(19.2 \%)$ & $22(56.4 \%)^{*}$ & 20 (29.9\%) & $12(50.0 \%)^{*}$ \\
\hline 3 & \multicolumn{2}{|c|}{ Number of people with fractures } & $4(7.7 \%)$ & $9(23.1 \%)^{*}$ & $4(6.0 \%)$ & $9(37.5 \%)^{*}$ \\
\hline \multirow{3}{*}{4} & \multirow{3}{*}{ Lumbar spine } & T-score, SD & $-0.86 \pm 0.14$ & $-1.41 \pm 0.19^{*}$ & $-0.94 \pm 0.13$ & $-1.51 \pm 0.23^{*}$ \\
\hline & & $\mathrm{BMD}, \mathrm{g} / \mathrm{cm} 2$ & $0.94 \pm 0.02$ & $0.86 \pm 0.02^{*}$ & $0.92 \pm 0.01$ & $0.86 \pm 0.03^{*}$ \\
\hline & & Z-score, SD & $-0.44 \pm 0.13$ & $-0.76 \pm 0.21$ & $-0.50 \pm 0.13$ & $-0.77 \pm 0.24$ \\
\hline 5 & \multicolumn{2}{|c|}{ Number of surveyed, $n$} & 26 & 28 & 43 & 11 \\
\hline \multirow{3}{*}{6} & \multirow{3}{*}{ Hip } & T-score, SD & $-0.55 \pm 0.18$ & $-1.14 \pm 0.23^{*}$ & $-0.73 \pm 0.12$ & $-1.56 \pm 0.36^{*}$ \\
\hline & & $\mathrm{BMD}, \mathrm{g} / \mathrm{cm} 2$ & $0.96 \pm 0.03$ & $0.90 \pm 0.03$ & $0.95 \pm 0.02$ & $0.84 \pm 0.04^{*}$ \\
\hline & & Z-score, SD & $-0.50 \pm 0.17$ & $-0.84 \pm 0.20$ & $-0.57 \pm 0.14$ & $-1.11 \pm 0.31$ \\
\hline
\end{tabular}

Note: * - significant $(p<0.05)$ differences regarding patients with low DI ( $<4$ points) and low SLEDAI $(<20$ points).

Table VI. BMD of lumbar spine and hip in SLE patients depending on serum IL-6

\begin{tabular}{|c|c|c|c|c|c|}
\hline \multirow{2}{*}{\multicolumn{2}{|c|}{$\begin{array}{l}\text { Groups of patients } \\
\text { Indicator }\end{array}$}} & & \multicolumn{2}{|c|}{ IL-6 } & \multirow[b]{2}{*}{$\begin{array}{l}\text { High IL-6 leve } \\
\text { (>20.0 ng/L) }\end{array}$} \\
\hline & & & $\begin{array}{l}\text { Optimal IL-6 level } \\
\text { (<12.5 ng/L) }\end{array}$ & $\begin{array}{c}\text { Extremely high IL-6 level } \\
(12.5-20.0 \mathrm{ng} / \mathrm{L})\end{array}$ & \\
\hline 1 & \multicolumn{2}{|c|}{ Number of surveyed in group, $\mathrm{n}$} & 24 & 39 & 21 \\
\hline 2 & \multicolumn{2}{|c|}{ Number of people with reduced BMD } & $5(20.8 \%)$ & $15(38.5 \%)$ & $11(52.3 \%)^{*}$ \\
\hline 3 & \multicolumn{2}{|c|}{ Number of people with fractures } & $2(8.3 \%)$ & $5(12.8 \%)$ & $6(28.6 \%)^{*}$ \\
\hline \multirow{3}{*}{4} & \multirow{3}{*}{ Lumbar spine } & T-score, SD & $-0.42 \pm 0.26$ & $-1.16 \pm 0.12^{*}$ & $-1.97 \pm 0.19^{*}$ \\
\hline & & $\mathrm{BMD}, \mathrm{g} / \mathrm{cm} 2$ & $0.98 \pm 0.03$ & $0.90 \pm 0.01^{*}$ & $0.81 \pm 0.02^{*}$ \\
\hline & & Z-score, SD & $0.13 \pm 0.30$ & $-0.61 \pm 0.11^{*}$ & $-1.38 \pm 0.20^{*}$ \\
\hline 5 & \multicolumn{2}{|c|}{ Number of surveyed in group, $\mathrm{n}$} & 16 & 25 & 13 \\
\hline \multirow{3}{*}{6} & \multirow{3}{*}{ Hip } & T-score, SD & $0.17 \pm 0.31$ & $-1.0 \pm 0.18^{*}$ & $-0.96 \pm 0.25^{*}$ \\
\hline & & $\mathrm{BMD}, \mathrm{g} / \mathrm{cm} 2$ & $1.01 \pm 0.03$ & $0.93 \pm 0.03^{*}$ & $0.82 \pm 0.03^{*}$ \\
\hline & & Z-score, SD & $-0.09 \pm 0.17$ & $-0.70 \pm 0.17^{*}$ & $-1.36 \pm 0.19^{*}$ \\
\hline
\end{tabular}

Note: * ${ }^{*}$ significant differences $(\mathrm{p}<0.05)$ regarding patients with optimal IL-6 levels.

of indicators was determined by the Shapiro-Wilk test. In our studies, there was a normal distribution of indicators, so the significance of the differences between groups was determined by the Student's t-test. To compare the significance of the differences between the relative values, Fisher's exact test was used. $\mathrm{P}<0.05$ was considered to be significant difference.

\section{RESULTS}

9.4\% of patients of reproductive age with SLE had reduced $\mathrm{BMD}$ in the lumbar spine and hip (Table I). During this period, no cases of bone loss were found in healthy individuals.

In postmenopausal women, osteoporosis in the lumbar spine was observed in 7 (18.4\%) patients with SLE, in the hip - in 3 (13.6\%). In the control group, osteoporosis was detected in $1(6.3 \%)$ person. Osteopenia occurred in almost every second patient with SLE and in 4 (25.0\%) people from the control group. Thus, the total proportion of people with reduced BMD among SLE patients was 32 (35.2\%) and 5 (17.2\%) among healthy individuals.

The BMD of both study areas in patients with SLE was also lower than in healthy individuals. Thus, the average lumbar spine BMD at reproductive age did not differ significantly in the control and main groups, and the hip BMD was $10 \%$ lower in patients with SLE. In postmenopausal women, the lumbar spine and hip BMD in healthy individuals was $0.99 . \pm 0.03 \mathrm{~g} / \mathrm{cm}^{2}$ and $1.01 \pm 0.03 \mathrm{~g} / \mathrm{cm}^{2}$ and was almost $10 \%$ higher than in patients with SLE.

Overall, the lumbar spine BMD in individuals from the main group was $0.90 \pm 0.01 \mathrm{~g} / \mathrm{cm}^{2}$, at the hip BMD $-0.93 \pm 0.02 \mathrm{~g} /$ $\mathrm{cm}^{2}$. In the control group, it was $0.97 \pm 0.02 \mathrm{~g} / \mathrm{cm}^{2}$ and $1.02 \pm$ $0.03 \mathrm{~g} / \mathrm{cm}^{2}$, respectively, and was on average $8.0 \%$ higher.

As for fragility fractures, they were detected in 13 (14.2\%) patients with SLE. In particular, $4(4.4 \%)$ had femoral neck fractures, and $9(9.9 \%)$ had vertebral body fractures. In the control group, fractures occurred in $3(10.3 \%)$ people, 1 (3.4\%) woman had a vertebral fracture and $2(6.9 \%)$ women had femoral neck fractures. 
The study found that one of the factors that negatively affect the bone tissue is the age of patients (Table II). In particular, there were no patients with reduced BMD and fractures in the age group of 22-35 years. The proportion of people with reduced BMD and fractures in the 36-55year group was $36.5 \%$ and $12.7 \%$, respectively. Among patients over 55 years of age, reduced BMD was observed in $75.0 \%$ of the examined patients, i.e more than twice as often as in 36-55-year-old individuals. During this period, the incidence of fractures was $41.7 \%$. BMD and average Zand $\mathrm{T}$-score in the lumbar spine and proximal femur also decreased in proportion to the age of the woman.

Bone loss in SLE patients was closely associated with disease duration (Table III).

These associations were more prominent in the lumbar spine. Thus, in people with disease duration up to 6 years BMD was equal to $0.97 \pm 0.02 \mathrm{~g} / \mathrm{cm}^{2}$, while in persons with disease duration of 6-10 years it was $0.89 \pm 0.03 \mathrm{~g} / \mathrm{cm}^{2}$, and in patients with disease duration more than 10 years it was $0.88 \pm 0.02 \mathrm{~g} / \mathrm{cm}^{2}$ or it was $9.2 \%$ lower. This was also confirmed by the increase in the proportion of people with reduced $\mathrm{BMD}$ among patients with moderate and high disease duration. In the latter two groups in particular, it was $25.0 \%$ and $50.0 \%$, respectively. The incidence of fractures was also higher in women with the highest disease duration ( $>10$ years).

An increase in the cumulative dose of glucocorticoids was found to have a negative effect on BMD in patients with SLE (Table IV). Thus, the lumbar spine BMD in patients with relatively low dose of glucocorticoids was significantly higher (9.2\% and $14.2 \%$, respectively) than in patients with high and very high cumulative dose of glucocorticoids. Similar changes were found in the hip. In both cases, an increase in the number of patients with reduced BMD and fragility fractures was observed.

The results of studies have shown that reduced BMD in women with SLE is closely related to the course of the disease - SLEDAI and the damage index (Table V). In particular, in persons with low disease activity (SLEDAI < 20 points), BMD in both study areas was on average $9.0 \%$ higher than in persons with high disease activity (SLEDAI $\geq 20$ points). In patients with high damage index (DI $\geq$ 4 points), the lumbar spine BMD was also significantly $(8.5 \%)$ lower than in women with $\mathrm{DI}<4$ points. The $\mathrm{T}$ and Z-score also decreased in proportion to the increase of inflammation and an increase in the damage index.

In women with SLE, increased serum IL-6 level also negatively affected the bone tissue (Table VI). Thus, in persons with high inflammation activity the lumbar spine BMD was $17.3 \%$ (the hip BMD - 18.8\%) lower than that at the optimal level of IL- 6 and was equal to $0.81 \pm 0.02 \mathrm{~g} / \mathrm{cm}^{2}\left(0.82 \pm 0.03 \mathrm{~g} / \mathrm{cm}^{2}\right)$ against 0.98 $\pm 0.03 \mathrm{~g} / \mathrm{cm}^{2}\left(1.01 \pm 0.03 \mathrm{~g} / \mathrm{cm}^{2}\right)$. Simultaneously with the increase in serum IL-6, the proportion of individuals with reduced BMD increased. Analysis of the number of fractures in patients with SLE showed the highest value of this indicator in women, with high values of IL-6.

\section{DISCUSSION}

The study showed that BMD decrease was observed among $35.2 \%$ of Ukrainian women with SLE and $17.2 \%$ of the control group. In particular, $11.3 \%$ of premenopausal patients had a Z-score below the expected range for age. In the postmenopausal period, osteopenia was detected in $50.0 \%$ of women with SLE, and osteoporosis - in $18.4 \%$. As for the healthy persons, there were no premenopausal women with BMD below the expected range for age. In the postmenopausal control group, the prevalence of osteoporosis and osteopenia was $6.3 \%$ and $25.0 \%$, correspondingly.

According to the research of Cramarossa G. et al. (2017), who, like us, have studied bone mineral density in women with SLE of different reproductive age using T- and Z-score and found that premenopausal women have reduced BMD in $17.3 \%$ of individuals. In postmenopausal women, osteopenia was detected in $43.2 \%$ of cases, and osteoporosis - in $12.3 \%$ [10].

Other data also indicate a high incidence of osteoporosis and osteopenia in patients with SLE. For example, osteoporosis was found in $1.4 \%$ and even in $68.0 \%$ of people, osteopenia $-25.0-74.0 \%$ of cases [2].

Bone mineralization evaluated by BMD was also significantly lower in patients with SLE. Thus, in the lumbar spine in the main study group, it averaged $0.90 \pm 0.01 \mathrm{~g} / \mathrm{cm}^{2}$, while in healthy individuals, $0.97 \pm 0.02 \mathrm{~g} / \mathrm{cm}^{2}$. The hip BMD in patients with SLE was $0.93 \pm 0.02 \mathrm{~g} / \mathrm{cm}^{2}$, and in the control group it was $1.02 \pm 0.03 \mathrm{~g} / \mathrm{cm}^{2}$. Our results fully coincide with the literature data. Wang et al. conducted a meta-analysis of 15 researches devoted to the study of the condition of bone tissue in patients with SLE. They report that patients with SLE suffer from an absolute reduction in BMD (an average of $0.06 \mathrm{~g} / \mathrm{cm}^{2}$ ), detected in the lumbar spine and femoral neck compared with the control group [11].

We have shown that in $14.2 \%$ of patients with SLE, fragility fractures occurred. The obtained data regarding the high prevalence of fractures in patients with SLE are consistent with the results of a number of studies. Thus, recent studies have demonstrated that high frequency (13.7-50\%) vertebral fractures are reported in SLE patients of both sexes, with every third patient having normal BMD [4, 12-15].

One of the adverse factors affecting the condition of bone tissue is the age of patients. According to the literature, older age is closely associated with reduced BMD in patients with SLE [10]. Similar patterns were found in our study. An analysis of the incidence of fractures showed that it was significantly higher among older SLE patients than among the youngest ones.

The negative effect of the duration of the disease on the condition of bone mineral density was established. In particular, T-score and the lumbar spine BMD progressively decreased with increasing time from the onset of the disease. Similar results were obtained in other studies $[10,16]$.

It is known that long-term use of glucocorticoids is a significant factor in determining the condition of bone tissue in patients with rheumatic diseases [17]. Recent studies have clearly indicated that there is no safe dose of glucocorticoids 
for bone tissue [18]. Our analysis of the relationship between $\mathrm{BMD}$ and glucocorticoids load revealed that the process of bone loss and, which results in fragility fractures, is associated with an increase in the cumulative dose of GC. In particular, BMD of both study areas at the cumulative dose of GC > $70.7 \mathrm{~g}$ was, on average, $13.2 \%$ lower than that of a relatively low GC. In addition, the proportion of patients with low BMD also increased significantly in proportion to the increase in cumulative dose of GCs. The obtained results confirm the data of other researchers [10, 19].

Another pathogenic factor of the adverse effect on bone tissue in patients with SLE is a systemic inflammatory process. An excess of pro-inflammatory cytokines (IL-1, IL-6, TNF- $\alpha$ ) induces osteoclastogenesis by enhancing osteoclast differentiation, contributing to increased RANKL synthesis and individual prostaglandins having resorptive activity [20]. However, the current views on this issue are quite contradictory. According to Pineau CA et al. (2004), García-Carrasco M et al. (2009), Cramarossa G et al. (2017), Sun YN et al. (2015) reduced BMD in patients with SLE was not associated with the inflammatory activity, while the overwhelming majority of scientists concluded that one of the predictors of osteoporosis is the damage index [10,21-26] and high disease activity [14, 27, 28].

Our research has shown that reduced BMD in women with SLE is associated with an increase in IL-6 and damage index. In particular, individuals with high inflammatory activity, the lumbar spine BMD was $17.3 \%$ lower $(18.8 \%$ - the hip BMD) than those with the optimal IL-6 level. The presence of fractures in women with SLE showed a very close dependence on the damage index, SLEDAI, as well as the level of IL-6. Thus, among individuals with high levels of IL-6, the proportion of individuals with fractures was 3.4 times higher than in the group with the optimal level of cytokine.

Thus, in patients with SLE there is a high frequency violation of bone tissue. The progressive decrease in BMD, which occurs not only during the aging process of a woman, is associated with a number of osteoporosis risk factors (duration of disease, high levels of inflammatory markers, use of glucocorticoids).

\section{CONCLUSIONS}

1. In $35.2 \%$ of women with SLE, reduced bone mineral density was observed. In particular, $11.3 \%$ of patients of reproductive age had Z-score below the expected range for age. In the postmenopausal period, osteopenia was found in $50 \%$ of women, osteoporosis - in $18.4 \%$. Reduced bone mineral density is associated not only with the age of patients, but also with the duration of the disease, damage index, the inflammatory activity and the cumulative dose of glucocorticoids.

2. Fragility fractures in women with SLE are found in 13 (14.2\%) persons, of which femoral neck fractures in $4(30.7 \%)$, vertebral body fractures in $9(69.3 \%)$. The presence of bone fractures has no association with the duration of the disease, but is also associated with the dose of GCs, disease course (IL-6 level, damage index) and age of patients.

\section{REFERENCES}

1. Guzon-Illescas 0. , Perez Fernandez E., CrespíVillarias N. et al. Mortality after osteoporotic hip fracture: incidence, trends, and associated factors. J Orthop Surg Res. 2019;14(1):203. doi: 10.1186/s13018-019-1226-6.

2. Bultink I.E.M. Bone disease in connective tissue disease/systemic lupus erythematosus. Calcif Tissue Int. 2018;102(5):575-591.

3. Kim C.S., Han K.D., Jung J.H. et al. Incidence and risk factors for osteoporotic fractures in patients with systemic lupus erythematosus versus matched controls. Korean J Intern Med. 2019. doi: 10.3904/ kjim.2018.378.

4. Carli L., Tani C., Spera V. et al. Risk factors for osteoporosis and fragility fractures in patients with systemic lupus erythematosus. Lupus Sci Med. 2016;3(1):e000098. doi: 10.1136/lupus-2015-000098.

5. Xia J., Luo R., Guo S. et al. Prevalence and Risk Factors of Reduced Bone Mineral Density in Systemic Lupus Erythematosus Patients: A Meta-Analysis. Biomed Res Int. 2019;2019:3731648. doi: 10.1155/2019/3731648.

6. Petri M., Bechtel B., Dennis G. et al. Burden of corticosteroid use in patients with systemic lupus erythematosus: Results from a Delphi panel. Lupus. 2014;23(10):1006-1013.

7. Aringer M., Costenbader K., Daikh D. et al. 2019 European League Against Rheumatism/American College of Rheumatology classification criteria for systemic lupus erythematosus. Ann Rheum Dis. 2019;78(9):1151-1159.

8. Bombardier C., Gladman D.D., Urowitz M.B. et al. Derivation of the SLEDAI. A disease activity index for lupus patients. The Committee on Prognosis Studies in SLE. Arthritis Rheum.1992;35(6):630-640.

9. Gladman D., Ginzler E., Goldsmith C. et al. The development and initial validation of the Systemic Lupus International Collaborating Clinics/ American College of Rheumatology damage index for systemic lupus erythematosus. Arthritis Rheum. 1996; 39(3):363-369.

10. Cramarossa G., Urowitz M.B., Su J. et al. Prevalence and associated factors of low bone mass in adults with systemic lupus erythematosus. Lupus. 2017;26(4):365-372.

11. Wang X., Yan S., Liu C. et al. Fracture risk and bone mineral density levels in patients with systemic lupus erythematosus: A systematic review and meta-analysis. Osteoporos Int. 2016;27(4):1413-1423.

12. Almehed K., Hetényi S., Ohlsson C. et al. Prevalence and risk factors of vertebral compression fractures in female SLE patients. Arthritis Res Ther. 2010;12(4):R153. doi: 10.1186/ar3104.

13. Borba V.Z., Matos P.G., Da Silva Viana P.R. et al. High prevalence of vertebral deformity in premenopausal systemic lupus erythematosus patients. Lupus. 2005;14(7):529-533.

14. Bultink I.E., Lems W.F., Kostense P.J. et al. Prevalence of and risk factors for low bone mineral density and vertebral fractures in patients with systemic lupus erythematosus. Arthritis Rheum. 2005;52(7):2044-2050.

15. Furukawa M., Kiyohara C., Horiuchi T. et al. Prevalence and risk factors of vertebral fracture in female Japanese patients with systemic lupus erythematosus. Mod Rheumatol. 2013;23(4):765-773.

16. Mori Y., Baba K., Kogure A. et al. Assessment of the risk of low bone mineral density in premenopausal Japanese female patients with systemic lupus erythematosus. J Orthop. 2018;15(1):89-93.

17. Seibel M.J., Cooper M.S., Zhou H. Glucocorticoid-induced osteoporosis: Mechanisms, management, and future perspectives. Lancet Diabetes Endocrinol. 2013;1(1):59-70.

18. Weinstein R.S. Clinical practice. Glucocorticoid-induced bone disease. N Engl J Med. 2011;365(1),62-70. 
19. Jacobs J., Korswagen L.A., Schilder A.M. et al. Six-year follow-up study of bone mineral density in patients with systemic lupus erythematosus. Osteoporos Int. 2013;24(6):1827-1833.

20. Amarasekara D.S., Yu J., Rho J. Bone loss triggered by the cytokine network in inflammatory autoimmune diseases. J Immunol Res. 2015;2015:832127. doi: 10.1155/2015/832127.

21. Almehed K., Forsblad d'Elia H., Kvist G. et al. Prevalence and risk factors of osteoporosis in female SLE patients-extended report. Rheumatology. 2007;46(7):1185-1190.

22. Becker A., Fischer R., Scherbaum W.A. et al. Osteoporosis screening in systemic lupus erythematosus: impact of disease duration and organ damage. Lupus. 2001; 10(11):809-814.

23. García-Carrasco M., Mendoza-Pinto C., Escárcega R.0. et al. Osteoporosis in patients with systemic lupus erythematosus. Isr Med Assoc J. 2009;11(8):486-91.

24. Lakshminarayanan S., Walsh S., Mohanraj M. et al. Factors associated with low bone mineral density in female patients with systemic lupus erythematosus. J Rheumatol. 2001;28(1):102-108.

25. Pineau C.A., Urowitz M.B., Fortin P.J. et al. Osteoporosis in systemic lupus erythematosus: factors associated with referral for bone mineral density studies, prevalence of osteoporosis and factors associated with reduced bone density. Lupus.2004;13(6),436-441.

26. Sun Y.N., Feng X.Y., He L. et al. Prevalence and possible risk factors of low bone mineral density in untreated female patients with systemic lupus erythematosus. Biomed Res Int. 2015;2015:510514. doi: $10.1155 / 2015 / 510514$.

27. Zhu T.Y., Griffith J.F., Au S.K. et al. Bone mineral density change in systemic lupus erythematosus: A 5-year followup study. J Rheumatol. 2014;41(10):1990-1997.

28. Guo Q., Fan P., Luo J. et al. Assessment of bone mineral density and bone metabolism in young male adults recently diagnosed with systemic lupus erythematosus in China.Lupus. 2017;26(3): 289-293.

\section{ORCID and contributionship:}

Sergii V. Shevchuk: 0000-0002-5649-2775 A,E,F

Liudmyla P. Denyshchych: 0000-0001-9366-8648 ${ }^{B, D}$

Liubov I. Marynych: 0000-0003-2191-3477 B,C

Inna P. Kuvikova: 0000-0003-1891-6263 C

Iryna V. Kurilenko: 0000-0001-5492-4573 ${ }^{B, D}$

Olena V. Shevchuk: 0000-0002-2357-2189 ${ }^{A, C}$

\section{Conflict of interest:}

The Authors declare no conflict of interest.

\section{CORRESPONDING AUTHOR Liudmyla P. Denyshchych \\ National Pirogov Memorial Medical University 56 Pirogova St., 21018 Vinnytsia, Ukraine tel:+380971495380 \\ e-mail: denishcich12@gmail.com}

Received: 09.03.2020

Accepted: 20.11 .2020

A - Work concept and design, B - Data collection and analysis, C - Responsibility for statistical analysis, D-Writing the article, $\mathbf{E}$ - Critical review, $\mathbf{F}$ - Final approval of the article 